\title{
ANÁLISE MACROSCÓPICA HEPÁTICA E ESPLÊNICA DE CÃES INFECTADOS POR Leishmania infantum NO MUNICÍPIO DE JOÃO PESSOA, PARAÍBA, BRASIL
}

\author{
Maria Railma Vieira de FREITAS $^{\mathbf{1}^{*}}$; Marcos Antônio Jerônimo COSTA ${ }^{\mathbf{2}}$; Felipe Eduardo da
} Silva SOBRAL ${ }^{3}$

\begin{abstract}
${ }^{\mathbf{1} B i o ́ l o g a / U n i v e r s i d a d e ~ E s t a d u a l ~ d a ~ P a r a i ́ b a ~(U E P B), ~ J o a ̃ o ~ P e s s o a, ~ P a r a i ́ b a, ~ B r a s i l . ~}$
${ }^{2}$ Graduado em Biologia/Universidade Federal da Paraíba (UFPB); Mestre em Ciências Biológicas/UFPB; Doutor em Ciências Biológicas/UFPB; Professor Titular/Universidade Estadual da Paraíba, João Pessoa, Paraíba, Brasil. ${ }^{3}$ Graduado em Medicina Veterinária/Universidade Federal de Campina Grande (UFCG); Mestre em Sistema Agrossilvipastoril no Semi-Árido/UFCG; Médico Veterinário autônomo e na Unidade de Controle Populacional de Cães e Gatos pela Prefeitura Municipal de João Pessoa (UCPCG/PMJP); Professor no curso de Medicina Veterinária/Centro Universitário Maurício de Nassau (UNINASSAU-PB), João Pessoa, Paraíba, Brasil.

*Autor para correspondência: E-mail: railmabio@gmail.com
\end{abstract}

A leishmaniose visceral (LV) é considerada o tipo mais grave dentre as leishmanioses. O agente etiológico é a Leishmania infantum, transmitido entre hospedeiros vertebrados por meio do inseto, Lutzomyia longipalpis, sendo os cães os principais reservatórios urbanos. As leishmanias são parasitas intracelulares obrigatórios que se reproduzem por divisão binária no interior das células do Sistema Fagocítico Mononuclear. O objetivo deste trabalho foi verificar as alterações morfológicas do baço e do fígado de cães acometidos por LV. Esse trabalho foi realizado no Centro de Controle de Zoonoses (CCZ) de João Pessoa Paraíba. Foram avaliados 30 cães, 25 com característica reagente para a imunofluorescência indireta e 05 não reagente, e agrupados em 03 grupos: sintomáticos, assintomáticos e controle. Após o procedimento eutanásico, foram tomadas as medidas externas das carcaças, necropsias e avaliações de baço e fígado e realizado à análise macroscópica destas vísceras: peso, coloração, textura e presença de lesões superficiais. A análise cadavérica evidenciou que, o peso relativo do fígado e o escore corporal dos animais apresentaram diferença estatística significativa entre os grupos estudados. $75 \%$ do grupo dos reagentes apresentaram fígados normais, $17 \%$ fígados anêmicos e $8 \%$ um quadro de congestão ou hiperemia. No baço $15 \%$ apresentavam-se normais, $18 \%$ anêmicos com hemorragias, $33 \%$ exclusivamente anêmico e $34 \%$ congestos com hemorragias. De acordo com os resultados é possível concluir que mesmo os animais sem nenhuma sintomatologia aparente (assintomáticos) apresentaram comprometimento visceral. Além disso, o baço é o órgão que apresenta mais injúrias superficiais, como hemorragias, congestão e anemia.

Palavras-chave: Baço; Cachorro; Calazar; Fígado; Leishmaniose visceral. 